\title{
Attitude and acceptability of assisted reproductive technology among women in a tertiary hospital in Sokoto, northern Nigeria
}

\author{
Amina G. Umar ${ }^{1 *}$, Aisha N. Adamu ${ }^{2}$ \\ ${ }^{1}$ Department of Obstetrics and Gynaecology, Usmanu Danfodiyo University, Sokoto, Nigeria \\ ${ }^{2}$ Department of Obstetrics and Gynaecology, Federal Medical Center, Kebbi State, Nigeria
}

Received: 01 January 2021

Revised: 10 February 2021

Accepted: 11 February 2021

\author{
*Correspondence: \\ Dr. Amina G. Umar, \\ E-mail: aminagamboobgy@gmail.com
}

Copyright: ( $)$ the author(s), publisher and licensee Medip Academy. This is an open-access article distributed under the terms of the Creative Commons Attribution Non-Commercial License, which permits unrestricted non-commercial use, distribution, and reproduction in any medium, provided the original work is properly cited.

\section{ABSTRACT}

Background: Infertility couple affects the couple's life, work, health, personality, identity and quality of life. The aim of the study is to determine the attitude and acceptability of assisted reproductive technology among women at the Usmanu Danfodiyo University Teaching Hospital, Sokoto.

Methods: This is a cross-sectional study that involved three 350 women attending infertility clinic. They were recruited via convenient sampling method using semi-structured questionnaire. The data obtained was managed using the statistical package for social sciences version 20. A p value of $<0.05$ was considered statistically significant and the result obtained was presented in charts and tables.

Results: Among the 350 women recruited, their ages ranged between 14-58 years with a modal age of 25-35 yeas $(58.0 \%)$ and a mean of $28.59 \pm 6.7$. They are mostly (78.6\%), of the Hausa/Fulani ethnic group. Almost all (98.9\%) of them were married and unto $40.5 \%$ of them were in polygamous marriage. Majority, $36.9 \%$ had tertiary education, and about same proportion, about half, $51.7 \% \%$ were gainfully employed. About $60.3 \%$ of them were nulliparae with a mean duration of infertility of $5.07 \pm 4.8$ years. Approximately half, $53.1 \%$ had secondary infertility and only about half, $51.4 \%$ will accept ART if offered. Unfortunately, among those who declined, majority (40.9\%) had no reason for doing so. There was statistically significant association between educational status and acceptance of assisted reproductive technology (ART) at $\mathrm{p}$ value 0.02 .

Conclusions: The acceptance of ART in our environment is influenced by the educational status and number of living children.

Keywords: Infertility, Assisted reproductive technology, Attitude, Acceptability, Sokoto

\section{INTRODUCTION}

In most African setting, parenthood is culturally mandatory and childlessness is socially unacceptable, this is because children are highly desired addition to the family and the society. ${ }^{1,2}$ In Nigeria, about $20 \%$ of couples are infertile. ${ }^{3}$ Female infertility was reported to account for about $55 \%$ of infertility cases, male factor for about $30 \%$ to $40 \%$ and unexplained infertility accounted for the remaining 5 to 15 percent. Infertility is generally known as a social stigma globally especially in the underdeveloped world. The agony and trauma of infertility is so devastating that only the victims that can understand and describe it. Although, it does not claim the life of an individual, but it inflicts devastating influence on one's life for not fulfilling the biological role of parenthood unintentionally. It is also known that in general, in the developing nation, the society has got a very strong desire for children and particularly for son to carry forth the lineage. ${ }^{4}$

With the enormous advances in the field of medicine, infertility can now be treated using the new medical 
technologies collectively called as assisted reproductive technology (ART) such as in vitro fertilization (IVF) or intracytoplasmic sperm injection (ICSI). The birth of the world's first child, Louise Brown, in 1978, through the technique of IVF was a path-breaking step in control of infertility; and is considered as one of the most important medical advances of the last century. ${ }^{4}$ In October 1978, the birth of the first test tube baby occurred in India using the cryopreserved embryo. Here in Nigeria, the first successful ART procedure was in 1989.,

There are different types of infertility and in some cases it would be physically or medically impossible/undesirable to carry a baby to term and hence, to fulfill the desire of such infertile couple to have a child, then surrogacy comes as an important option. ${ }^{7}$

ART refer to all forms of treatments or procedures that include the in vitro handling of human oocytes and sperm or embryos for the purpose of establishing a pregnancy. ${ }^{8}$ It includes: the use of donor gametes for men and women with absent or dysfunctional gonads, surrogacy for women with absent or damaged uteri; and child adoption as a method of overcoming infertility. Surrogacy is, however, fraught with ethical, legal, moral, emotional and psychological dilemmas and difficulties. ${ }^{3}$ ARTs including IVF with fresh or frozen embryos as well as ICSI use are in the increase in developed countries since the late 1970s, solving more than 50 per cent of infertility cases. ${ }^{9-12}$

Multiple studies have failed to find a clinically relevant association between IVF or embryo cryopreservation and adverse maternal or fetal effects. ${ }^{13}$ Other studies have suggested that infants of IVF pregnancies may be at a small but statistically significant increased risk for rare epigenetic and other abnormalities. ${ }^{14}$ Overall, there is a general consensus that IVF confers a small but measurable increased risk for a variety of congenital abnormalities including anatomic abnormalities and imprinting errors as compared to the general population. ${ }^{14}$ Some maintain, however, that this is secondary to an increased baseline risk for these problems in the population of infertile patients. ${ }^{14}$ Regardless of the cause, this small increased risk, while statistically significant with extremely large sample sizes, will likely not be a powerful enough factor to dissuade infertile couples from pursuing parenthood through IVF.

Despite above problem and remedies, the acceptability of ART and subsequently its adoption is contextually influenced by the prevailing socio-cultural factors, especially the religious system. ${ }^{15}$ In some parts of the world about the procedure and babies born through IVF has been split between acceptance, reservation, and in some instances rejection, particularly in some aspects such as third-party involvement. Religion, culture, personal belief, and cost are some factors that affect the acceptance by the public. In a study, $73.5 \%$ would opt for ART and $35.6 \%$ found high cost hindering the acceptance. A total of $31.1 \%$ of them did not believe in ART and said only god gives babies and $25.6 \%$ thought that ART babies are artificial. $^{16,17}$

Therefore, the aim of this study of this study is to assess the attitude and acceptability of assisted reproductive technology among infertile women at the Usmanu Danfodiyo University Teaching Hospital, Sokoto.

\section{METHODS}

This was a cross-sectional study conducted over a period of six months from August 2018 to January 2019. Three hundred and fifty women were recruited by convenience sampling method via the infertility clinic of the Department of Obstetrics and Gynaecology, Usmanu Danfodiyo University, Sokoto using semi-structured interviewer questionnaires. Information regarding their socio-demographic character, obstetrics, medical, surgical and social history was obtained, in addition to their attitude and acceptance of assisted reproductive technique.

The result obtained was analysed using the statistical software package for social sciences (SPSS) version 20 and a $\mathrm{p}$ value of $<0.05$ was considered statistically significant. The results obtained was presented in text, tables and charts. Ethical approval was obtained from the Institution's Ethics and Research Committee.

\section{RESULTS}

Three hundred and fifty women were recruited with age range between 14-58 years, modal age of 25-35 yeas $(58.0 \%)$ and a mean of 28.59 \pm 6.66 . Majority, 275 (78.6\%) were Hausa/Fulani ethnic group and other minority tribes constituted the rest of the respondents. They were mostly $(98.9 \%)$ married and $196(59.5 \%)$ were in monogamous marriage while, the remaining $(40.5 \%)$ were in polygamous family, and $2(0.6 \%)$ each are widowed and divorcee. Majority $129(36.86 \%)$ tertiary education and about half 181 (51.71\%) of them were gainfully employed. About two third, 211 (60.29\%) of them were nulliparae while, $118(33.71 \%)$ were of low parity (para 1-3) and 21 (6\%) had high parity (para 4-6). Details of their sociodemographic characteristics is as shown in Table 1.

Majority 186 (53.14\%) had secondary infertility while 164 $(46.86 \%)$ had primary infertility. The duration of infertility ranged from 1 year to 34 years with a mean duration of $5.07 \pm 4.836$ years

Among them, 179 (51.4\%) would accept ART if offered and the rest declined. Surprisingly, majority, 103 (85.83\%) had no reason to decline. The proportion of acceptance of ART is as shown in Figure 1.

The main reason for declining in up to $50(41.67 \%)$ was high cost, of treatment. Up to $56.5 \%$ believed that such babies are normal and natural. Other reasons for declining ART procedure are as shown in Figure 2. 
Table 1: Socio-demographic characteristics.

\begin{tabular}{|c|c|c|}
\hline Variable & Frequency & Percentage $(\%)$ \\
\hline \multicolumn{3}{|l|}{ Age group (years) } \\
\hline $14-24$ & 99 & 28.29 \\
\hline $25-35$ & 203 & 58.00 \\
\hline $36-46$ & 39 & 11.14 \\
\hline $47-57$ & 5 & 1.43 \\
\hline$\geq 58$ & 4 & 1.14 \\
\hline \multicolumn{3}{|l|}{ Educational status } \\
\hline No formal/Qur'anic & 69 & 19.71 \\
\hline Primary & 44 & 12.57 \\
\hline Secondary & 108 & 30.86 \\
\hline Tertiary & 129 & 36.86 \\
\hline \multicolumn{3}{|l|}{ Occupation } \\
\hline Unemployed & 169 & 48.29 \\
\hline Trader & 46 & 15.14 \\
\hline Business women & 27 & 7.71 \\
\hline Teachers & 30 & 8.57 \\
\hline Others & 78 & 22.29 \\
\hline Tribe & 275 & \\
\hline Hausa/Fulani & 25 & 78.6 \\
\hline Igbo & 18 & 3.1 \\
\hline Yoruba & 32 & 9.1 \\
\hline \multicolumn{3}{|l|}{ Others } \\
\hline \multicolumn{3}{|l|}{ Parity } \\
\hline \multicolumn{3}{|l|}{0} \\
\hline \multicolumn{3}{|l|}{$1-2$} \\
\hline \multicolumn{3}{|l|}{$3-4$} \\
\hline \multicolumn{3}{|l|}{5 and above } \\
\hline Total & 350 & 100.00 \\
\hline
\end{tabular}

Majority of those within the age of 36 to 46 years (52.8\%), and 58 years and above (100\%) will accept ART. However, it was not statistically significant. There was statistically significant association between educational status and acceptance of assisted reproductive technique at a p value 0.002 . As up-to $60.2 \%$ of those with secondary school education will accept if offered. Although, more than half of the Yoruba's, 58.8\% and other minority groups will accept compared to Hausa/Fulani and Igbo's, it was not statistically significant at $\mathrm{p}$ value $=0.56$.

It is surprising that more than half, $63.7 \%$ of the nulliparae were not interested and another $2 \%$ do not know if they would accept. It is not surprising that a high acceptance, $86.7 \%$ was also observed among those with 1-2 living children, and that was statistically significant at $\mathrm{p}$ value 0.015 .

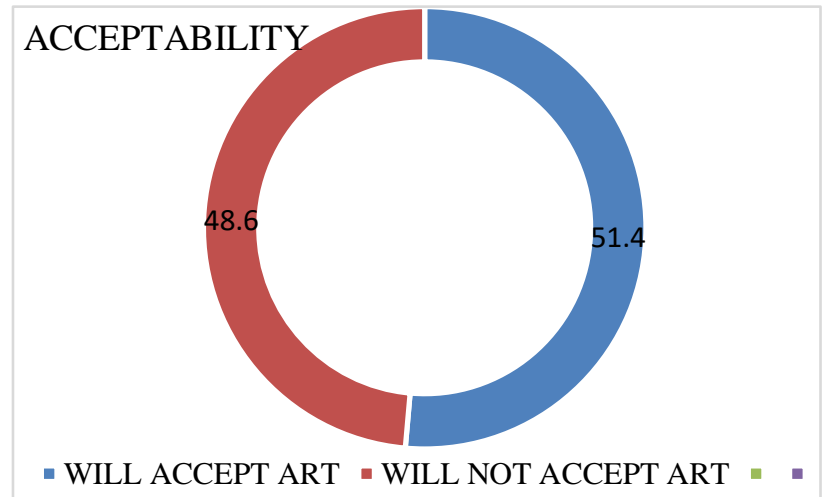

Figure 1: Proportion of acceptance of ART by the respondents.

Among those who will accept ART, 137 (59.6\%) will prefer multiple gametes at point of transfer. With regards to preference for source of gamete, $77(33.5 \%)$ will prefer self-gamete and $23(10 \%)$ will accept donor, while only 20 $(8.7 \%)$ will go for corrugate mother when necessary.

Only $22(9.6 \%)$ and $17(4.9 \%)$ will accept donating ovum or husband's sperm for ART respectively, as well as 18 $(7.8 \%)$ accepted participating as surrogate mothers.

Overall, majority will go for self-gamete compared to donation across board.

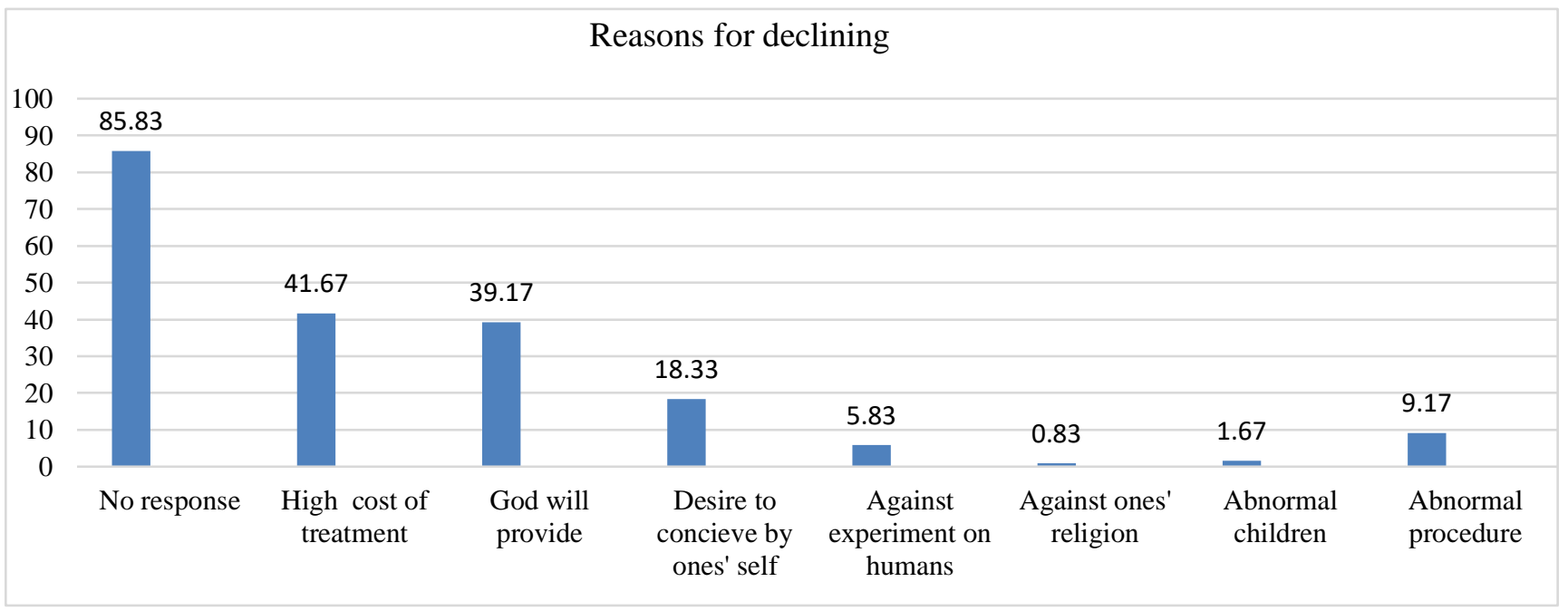

Figure 2: Reason for declining ART procedure by respondents. 


\section{DISCUSSION}

In this study, the mean age of the respondents was 28.59 \pm 6.66 with 25-35 years comprising 58\% of them. This is in conformity with $31 \pm 5.003$ year reported from Iran and mostly within 30-39 years from Benin, Nigeria. ${ }^{18,19}$ It is however lower than 38.3 years and age range of 46 to 50 years in the majority reported by Okwelogu in Anambra, 34.38 years from Ibadan and 34.8 years from Zaria, Nigeria and $34.3 \pm 5.5$ years from southsouth. ${ }^{1,20-22}$ This could be as a result of the relative delayed child bearing attitude in the southern part of the country compared to the North.

Majority 275 (78.6\%) were Hausa/Fulani ethnic group and Muslims. This is so because the environment is a Hausa/Fulani dominated community. This is contrary to Christians and Igbo ethnic group in the southern part of the country. ${ }^{18,22}$

They were mostly, $98.9 \%$ married and $59.5 \%$, in monogamous. This is surprising as the study was conducted in a community where polygamy is the norm. This is comparable to what was reported from Benin, Nigeria where most, $85.4 \%$ of the respondents were married and in monogamous setting. ${ }^{20}$ Similarly, $92.1 \%$, Yoruba and up to $98.5 \%$ were married. However, $50.0 \%$ were also Muslims as reported from Ibadan, South western, Nigeria. ${ }^{21}$

$55.5 \%$ had tertiary school education while only $59.4 \%$ were traders/artisans.

Majority, $36.86 \%$ of the respondents in this study had tertiary education and $30.86 \%$ had secondary education. This is contrary to secondary education in $52.8 \%$ and $51.7 \%$, and $37.1 \%$ and $40.4 \%$ tertiary education reported by others. ${ }^{18,20}$ About half, $51.71 \%$ of them were gainfully employed. This is lower than $81 \%$ reported in another study. ${ }^{18}$ It is not surprising since majority of the respondents in both studies were educated and that can modify the attitude of self-reliance and health seeking behavior.

In this study revealed that about two-third, $60.29 \%$ of the respondents were nulliparae. This is comparable to $62 \%$, as the studies were conducted among infertile women, nulliparae have higher tendency of acceptance. ${ }^{20}$

This study revealed that, $53.14 \%$ had secondary infertility while, $46.86 \%$ had primary infertility. This is agreeing with $66 \%$ and $34 \%$ reported for secondary and primary infertility respectively. ${ }^{18}$ It also agreed with $82.0 \%$ for secondary and $18.0 \%$ for primary infertility. ${ }^{22}$ It is however, contrary to $54.5 \%$ primary infertility and $45.5 \%$ secondary infertility reported by Akande at Ibadan. ${ }^{21}$ The high rate of secondary infertility in most centers is as a result of the high prevalence of pelvic infections in resource poor countries.
In this study, the duration of infertility ranged between 1 to 34 years and, up to $55 \%$ had duration of 10 years and above with a mean of $5.07 \pm 4.836$ years. This is similar to 4.1 years however, not in agreement with a range of 1 to 12 years. $^{22}$ It is contrary to mean duration of 11 years and $27 \%$ having 10 years and more. ${ }^{1,18}$ It is also contrary to mean duration of $7.3 \pm 5.8$ years but in support of range of 1 to 33 years from Ilorin. ${ }^{6}$

Among all the respondents studied, 51.4\% would accept ART if offered. Surprisingly, majority, $85.83 \%$ had no reason to decline. It may however, be due to socio-cultural reasons that prevented them from expressing their opinions. This is in conformity with $42.0 \%$ reported from Ibadan. ${ }^{21}$ It was however, higher than $37.2 \%$ reported by Okwelogu and $7.6 \%$ from Kano which was mainly influenced by high educational status and being nonMuslim. $^{8,23}$ It is however, lower than $92 \%$ reported from Zaria. ${ }^{1}$ It is noteworthy that there was no difference among those with primary or secondary infertility in terms of acceptance. However, it was found out that those with fewer number of living children had higher rate of acceptance compared to higher number. This is contrary to the study conducted by Akande who reported higher acceptance rate among those with primary infertility. ${ }^{21}$

Among those who will accept, 59.6\% will prefer multiple gametes at point of transfer and with regards to preference for source of gamete, $33.5 \%$ will prefer self-gamete. Both are in agreement with other studies. ${ }^{1,18,20}$ This is not surprising because cultural and religious factors play major role in such decision making. The main reason for declining in up to $41.67 \%$ was high cost, of treatment. This is in conformity with other studies. ${ }^{15,18,20,24}$ Others also believed that it may not be effective like the natural conception and therefore may not be reliable. ${ }^{15}$ The negative attitude towards high cost may be attributed to the overwhelming low level of living standards among majority of the populace, posing the procedure nonaccessible and non-affordable by the common man.

Among the study participants who consented to ART, $59.6 \%$ will prefer multiple gametes at the point of transfer and with regards to preference for source of gamete, $33.5 \%$ will prefer self-gamete. Both are in agreement with other studies. ${ }^{15,18,20,24}$ However, only $9 \%$ and $4.9 \%$ will accept donating ovum or husband's sperm for ART respectively, as well as $7.9 \%$ acceptance to offer surrogacy. This is higher than $37.2 \%$ acceptance in another study due to the belief that the babies are abnormal. ${ }^{18}$ In addition, $81.4 \%$ of those that accepted will prefer self-gamete, however, none was interested in surrogacy. ${ }^{18}$ Similarly, a study from Ibadan, among those unwilling to utilise ART procedure reported exorbitant cost of the services in almost all the respondents, 98.8\%. ${ }^{21}$ Among them, 88.2\% would prefer natural conception, $47.1 \%$ believed in god's intervention and $45.9 \%$, believed the procedures may result to deformed and abnormal babies. Another substantial proportion, $53.0 \%$ preferred spiritual intervention as an alternative to ART. 
With regards to number gametes to be transferred, $91.4 \%$ of subjects in another study preferred multiple gametes to singleton. Additionally, a few respondents (10.7\%) were willing to make use of donors' sperm, while $10.6 \%$ will accept donors' ovum for conception. Of those willing to adopt ART, only $15.0 \%$ were optimistic that the procedures will be successful. ${ }^{21}$

\section{Limitations}

The convenience sampling method may alter the result and therefore affects the power of the study. The study may not be a true reflection of the population as a result of the small sample size within an institution.

\section{CONCLUSION}

The attitude towards ART was not encouraging as majority had negative thoughts toward ART. Although, acceptance was relatively good, it was influenced by educational status and fewer number of living children.

This implies that there is a long way to go by stakeholders in ensuring attitudinal changes among the populace to bring about positive thoughts to improve acceptability so as to minimize trauma due to infertility.

\section{ACKNOWLEDGMENTS}

Authors would like to acknowledge the clients who gave consent to participate and the hospital management that granted approval to undertake the study.

Funding: No funding sources

Conflict of interest: None declared

Ethical approval: The study was approved by the Institutional Ethics Committee

\section{REFERENCES}

1. Adesiyun AG, Ameh N, Avidime S, Muazu A. Awareness and perception of assisted reproductive technology practice amongst women with infertility in Northern Nigeria. Open J Obstet Gynecol. 2011;1:144-8.

2. World Health Organization (WHO). Mother or nothing: the agony of infertility. WHO Bulletin: 2010;88(2):877-953.

3. Bello FA, Akinajo OR, Olayemi IO. In-vitro fertilization, gamete donation and surrogacy: Perceptions of women attending an infertility clinic in Ibadan, Nigeria. Afr J Reprod Health. 2014;18(2):127-33.

4. World's first "test tube" baby born. Available at: https://www.history.com/this-day-in-history/worldsfirst-test-tube-baby-born. Accessed on 02 November 2020.

5. Kamel RM. Assisted Reproductive Technology after the Birth of Louise Brown. J Reprod Infertil. 2013;14(3):96-109.
6. Omokanye LO, Olatinwo AO, Salaudeen GA, Durowade KA, Panti AA, Balogun RO. Assisted reproductive technology in Nigeria: challenges and the way forward. Afr $\mathrm{J}$ Infert Assist Concept. 2018;3(1):2-5.

7. Van Landuyt L, Verheyen G, Tournaye H, Camus M, Devroey P, Van Steirteghem A, et al. New Belgian embryo transfer policy leads to sharp decrease in multiple pregnancy rate. Reprod Biomed Online. 2006;13:765-71.

8. Malhotra N, Shah D, Pai R, Pai HD, Bankar M. Assisted reproductive technology in India: a 3 year retrospective data analysis. J Hum Reprod Sci. 2013;6:235-40.

9. Kirby RS. Assisted Reproductive Technology and Development Outcomes. Pediatrics. 2018;142(6):20183072.

10. Pandian Z, Templeton A, Serour G, Bhattacharya S. Number of embryos for transfer after IVF and ICSI: A cochrane review. Hum Reprod. 2005;20:2681-7.

11. Cooke ID. The globalization of reproductive technology. In: Kruger TF, van der Spuy Z, Kemper BD (eds). Advances in fertility studies and reproductive medicine. Cape Town, Juticalpa. 2007;234-40

12. Government of Canada. Assisted Human Reproduction Act, SC 2004. Available at: http://lawslois.justice.gc.ca/eng/acts/a-13.4. Accessed on 03 June 2013.

13. Wennerholm UB, Söderström-Anttila V, Bergh C, Aittomäki K, Hazekamp J, Nygren KG, et al. Children born after cryopreservation of embryos or oocytes: a systematic review of outcome data. Hum Reprod. 2009;24:2158-72.

14. Brezina PR, Zhao Y. The ethical, legal, and social issues impacted by modern assisted reproductive technologies. Obstet Gynecol Int. 2012;686253.

15. Olusola AS, Jegede AS. The effects of native culture and religious beliefs on human infertility and assisted reproductive treatment: a focus on the Ijebu people of Nigeria. Afr J Soc Sci. 2014;4(4):88-102.

16. Adenike MO, Adebimpe Wasiu O, Olarewaju Sunday O, Olaniyan B. Prevalence of infertility and acceptability of assisted reproductive technology among women attending gynecology clinics in tertiary institutions in Southwestern Nigeria. Open J Obstet Gynecol. 2014;4:7-1.

17. Olugbenga B, Adenike I, Adebimpe W, Sunday O. Prevalence of infertility and acceptability of assisted reproductive technology among women attending gynecology clinics in tertiary institutions in Southwestern Nigeria. Gynecol Obstet (Sunnyvale). 2014;4:3.

18. Afshani SA, Abdoli AM, Hashempour M, Baghbeheshti M, Zolfaghari M. The attitudes of infertile couples towards assisted reproductive techniques in Yazd, Iran: a cross sectional study in 2014. Int J Reprod Biomed. 2016;14:761-8.

19. Aziken ME, Orhue AA, Kalu OO, Osemwemkha PA. Knowledge, perception and attitude of infertile 
women in Benin city, Nigeria to the causation of infertility and in vitro fertilisation and embryo transfer. Trop J Obstet Gynaecol. 2010;27:40-5.

20. Okwelogu IS, Azuike EC, Ikechebelu JI, Nnebue CKC. In-vitro fertilization practice: awareness and perceptions among women attending fertility clinics in Okija, Anambra state, Nigeria: Afr Med J. 2012;3:82.

21. Akande SO, Dipeolu IO, Ajuwon AJ. Attitude and willingness of infertile persons towards the uptake of assisted reproductive technologies in Ibadan, Nigeria. Ann Ibadan Pg Med J. 2019;17(1):51-8.

22. Kissin DM, Kulkarni AD, Kushnir VA, Jamieson DJ. Number of embryos transferred after in vitro fertilization and good perinatal outcome. Obstet Gynecol. 2014;123(201):239.
23. Iliyasu Z, Galadanci HS, Abubakar IS, Bashir FM, Salihu HM, Aliyu MH, et al. Perception of infertility and acceptability of assisted reproduction technology in Northern Nigeria. Niger J Med. 2013;22:341-7.

24. Écra AFT, Koffi AK, Aka KE, Fomba M, Konan P. Acceptability of gametes donation in Côte d'Ivoire. Open J Obstet Gynecol. 2017;7:400-10.

Cite this article as: Umar AG, Adamu AN. Attitude and acceptability of assisted reproductive technology among women in a tertiary hospital in Sokoto, northern Nigeria. Int J Reprod Contracept Obstet Gynecol 2021;10:1770-5. 